\title{
Zinc-binding capacity of yak casein hydrolysate and the zinc-releasing characteristics of casein hydrolysate-zinc complexes
}

\author{
X. Wang, ${ }^{*}$ J. Zhou, ${ }^{*}$ P. S. Tong, $†$ and X. Y. Mao*1 \\ ${ }^{*}$ Key Laboratory of Functional Dairy Science of Beijing and Ministry of Education, College of Food Science and Nutritional Engineering, \\ China Agricultural University, Beijing 100083, China \\ †Dairy Products Technology Center, California Polytechnic State University, San Luis Obispo 93407
}

\section{ABSTRACT}

Many factors affect the bioavailability of dietary Zn, which leads to its low availability in some food systems and $\mathrm{Zn}$ nutrient deficiency. However, some proteins or peptides can form complexes with $\mathrm{Zn}$ and increase its absorption and bioavailability in intestinal conditions. The purpose of this work was to determine the $\mathrm{Zn}$ binding activity of yak casein hydrolysate $(\mathrm{YCH})$ and examine its stability, solubility, and dialyzability in a simulated intestinal environment. The Zn-binding activity of $\mathrm{YCH}$, prepared using alcalase, pepsin, trypsin, Flavozyme (Novo Nordisk Biochem Inc., Franklinton, $\mathrm{NC}$ ), or papain, was investigated. Evidence for the formation of complexes between $\mathrm{Zn}$ and $\mathrm{YCH}$ also were detected by UV-visible spectroscopy and Fourier transform infrared spectroscopy. Results were that YCH prepared with alcalase and trypsin possessed the highest Zn-binding capacity compared with YCH prepared with pepsin, Flavozyme, or papain. The 6-h YCH obtained with alcalase showed the highest Zn-binding capacity. Compared with native yak casein, the Znbinding activity of $\mathrm{YCH}$ was significantly lower, but its solubility and dialyzability were markedly higher under intestinal basic $\mathrm{pH}$ ranges. This is important because high solubility and dialyzability is associated with better bioavailability. Both UV-visible spectroscopy and Fourier transform infrared spectroscopy spectra indicated that some sites of $\mathrm{YCH}$ can bind with $\mathrm{Zn}$ ions and form complexes that make $\mathrm{Zn}$ more soluble and dialyzable under simulated intestinal conditions. Therefore, YCH-Zn complexes may have potential to improve Zn bioavailability.

Key words: yak casein hydrolysate, zinc-binding capacity, dialyzability, spectra characteristic

Received October 5, 2010.

Accepted December 31, 2010.

${ }^{1}$ Corresponding author: maoxueying@cau.edu.cn

\section{INTRODUCTION}

Zinc is required for many physiological functions that can affect human growth and development. Subclinical Zn deficiency is prevalent, particularly in the elderly and children (Maret and Sandstead, 2006). It may lead to growth retardation, impaired immune function, alopecia, delayed skeletal maturation and dermatitis, increased morbidity, and decreased neurocognitive development (Hambidge, 1986; Fairweather-Tait and Hurrell, 1996). Zinc absorption depends not only on the amount consumed but also its bioavailability, which, in turn, is affected by the different components of dietary foods. Dietary Zn is usually poorly absorbed especially from plant-based foods because of the high content of phytate, which is an important inhibitor of Zn absorption (Fredlund et al., 2006). Zinc deficiency is common in populations consuming this type of plant-based diet. Numerous dietary factors have been investigated as a possible determinant of $\mathrm{Zn}$ bioavailability from foods. Soluble, low-molecular weight organic substances such as some AA and organic acids can act as Zn-binding ligands and facilitate Zn absorption (Harzer and Kauer, 1982; Miquel and Farre, 2007). Therefore, from a nutritional point of view, it is important to improve the content of bioavailable dietary Zn. However, little information on how to improve the bioavailability of $\mathrm{Zn}$ is available.

Many factors can affect the bioavailability of dietary $\mathrm{Zn}$ in dairy food systems. Some proteins or peptides can form complexes with minerals, which make minerals soluble and increase their absorption and bioavailability in intestinal basic conditions (Chaud et al., 2002). Peptides obtained from casein hydrolysis have been shown to bind minerals such as calcium and increase their absorption (FitzGerald, 1998; Vegarud et al., 2000). Many studies have focused on the role of casein phosphopeptides (CPP) from enzyme hydrolysis to enhance calcium bioavailability (Ferraretto et al., 2003; Narva et al., 2003) or Fe bioavailability (Aît-Oukhatar et al., 2000; Chaud et al., 2002). Casein phosphopeptides contain a cluster sequence SpSpSpEE (i.e., highly 
polar acidic sequence of 3 phosphoserines, followed by 2 glutamic acid residues). These sequences represent the binding sites for minerals. The reaction of ferric chloride with a casein enzymatic hydrolysate could form $\mathrm{Fe}^{3+}$-peptide complexes, which may have potential as an Fe supplement (Chaud et al., 2002). In vitro digestion is incapable of releasing dialyzable $\mathrm{Fe}$ when $\mathrm{Fe}$ is bound to $\beta-\mathrm{CN}(1-25)$ (Aît-Oukhatar et al., 2000). Iron bound to $\beta-\mathrm{CN}(1-25)$ is speculated to be absorbed by a different pathway from that of inorganic Fe (Peres et al.,1997). In our previous work, we found that yak casein hydrolysate $(\mathbf{Y C H})$ possessed Fe-binding activity, and formed YCH-Fe complexes, which were more soluble than $\mathrm{FeSO}_{4}$ at basic $\mathrm{pH}$ range (Mao et al., 2008). However, the effect of protein hydrolysate on Zn solubility and dialyzability has been less extensively investigated.

Yak milk is the most common dairy product in northwestern China, such as the areas of Gansu, Xinjiang and Tibet. In these areas, people only use it for the production of butter. Although the byproduct Qula (a crude cheese, whose main component is casein) is consumed in these regions, it is a perishable product. Therefore, improving the economic value and demand of Qula has received great attention from the Chinese government. Although Qula contains some fat, lactose, and minerals, the casein content of Qula is high (more than $80 \%$ on a dry weight basis). Hence, it has some properties of acid casein. In fact, in some places where there is excess Qula, it is collected and processed into sodium caseinate.

In addition, the AA compositions of yak milk caseins are very similar to those of cow milk caseins (Ochirkhuyag et al., 1997). Our previous study showed that yak casein (YC)-derived peptides possess antihypertensive, immunoregulatory activities (Mao et al., 2007a,b) and Fe-binding activity (Mao et al., 2008). The above-mentioned studies show that bovine casein hydrolysate improves mineral bioavailability. Miquel and Farre (2007) reported that the use of preformed $\mathrm{Zn}$ complexes prevented $\mathrm{Zn}$ precipitation and interactions with other metals and, consequently, improved Zn bioavailability. On the basis of these findings and the similarities of the primary structure between bovine casein and $\mathrm{YC}$, we hypothesized that $\mathrm{YCH}$, as an intestine-permeable $\mathrm{Zn}$ ligand, could properly bind with $\mathrm{Zn}$ and improve Zn solubility and, ultimately, Zn bioavailability. Moreover, the formed YCH-Zn complexes, which make Zn highly soluble, may have the potential to be used as an ingredient in foods. Additionally, if bitterness can be overcome, limited hydrolysis of YC may provide a technological solution to address $\mathrm{Zn}$ and other mineral deficiencies. Whey protein hydrolysates are produced primarily for specific food functions (e.g., texture control, protein solubility, among others) However, several studies have shown that hydrolysis of whey protein does improve mineral-binding activity (Svenning and Vegarud, 1998; Kim et al., 2007; Kamijima et al., 2008).

The choice of proteolytic enzymes is very important to in vitro digestion processes because enzyme specificity influences the composition of digestion products, and different enzymes have different specificity to peptide bonds. Pepsin is known to cleave peptide bonds that involve AA with large hydrophobic side-chains, such as Phe and Leu (Webb, 1992). Trypsin preferentially attacks hydrophilic Lys and Arg residues (Alder-Nissen, 1986). So the effect of different kinds of proteinases on the Zn-binding capacity of the obtained hydrolysates was investigated in the present work.

Therefore, this work was carried out to determine the proper enzymatic conditions to convert yak caseinate into a good source of Zn-binding peptides, evaluate the binding activity of $\mathrm{YCH}$ with $\mathrm{Zn}$, and investigate the binding characteristics and $\mathrm{Zn}$ bioavailability of $\mathrm{YCH}$ and its Zn complex.

\section{MATERIALS AND METHODS}

\section{Materials and Reagents}

Qula (yak casein) was provided by Hua-Ling Ltd. Company (Lanzhou, Gansu Province, China). Alcalase (E.C.3.4.21.62; endoproteinase from Bacillus licheniformis) $2.4 \mathrm{~L}$ with a declared activity of 2.4 Anson units (AU) per gram was provided by Novo Nordisk Biochem Inc. (Franklinton, NC). Pepsin (EC.3.4.23.1; Sigma, St. Louis, MO); trypsin (EC.3.4.21.4, activity 2-4 U/mg, Gibco-BRL, Grand Island, NY); papain (EC 3.4.4.10; Sigma-Aldrich, St. Louis, MO) and Flavozyme (Novo Nordisk Biochem Inc.) were obtained from Genetic Biochemical Products Ltd. (Wuxi, China). Zinc acetate dihydrate was purchased from Beijing Chemical Co. (Beijing, China). Potassium bromide $[\mathrm{KBr}$, Fourier transform infrared spectroscopy (FTIR) grade] was acquired from Sigma-Aldrich. All other chemicals were reagent grade.

\section{Preparation of Yak Casein Hydrolysate}

Yak casein hydrolysate was prepared according to the method of Mao et al. (2007b). Casein was hydrolyzed with alcalase, pepsin, trypsin, Flavozyme, and papain, respectively, using a hydrolysis reactor equipped with a stirrer, $\mathrm{pH}$ electrode, and thermometer. Samples were collected at periodic intervals of hydrolysis time $(0,1$, $2,3,4,5,6,7,8,9$, and $10 \mathrm{~h}$ ) by removing $50-\mathrm{mL}$ aliquots using a glass pipette. Proteases in each sample 
were immediately inactivated by heating the samples in an $85^{\circ} \mathrm{C}$ water bath for $15 \mathrm{~min}$, and then cooling them to room temperature. The enzymatic hydrolysates were ultrafiltered with a 10,000-Da molecular weight (MW)cut-off membrane (Sartorius Co., Goettingen, Germany) to remove the enzyme and the nonhydrolyzed proteins. The permeate was collected and lyophilized with a vacuum freeze dryer (Songyuanhuaxing Technology Develop Co. Ltd., Beijing, China).

\section{Formation of Yak Casein-Zinc Complexes and Yak Casein Hydrolysate-Zinc Complexes}

Yak casein hydrolysates were dissolved in deionized water. To obtain $\mathrm{YCH}-\mathrm{Zn}$ complexes, $\mathrm{Zn}$ acetate was added to each $\mathrm{YCH}$ solution and incubated in a $37^{\circ} \mathrm{C}$ shaking water bath for $40 \mathrm{~min}$. The resulting solutions were then dialyzed with a 500-Da MW-cut-off semipermeable membrane to remove the unbound $\mathrm{Zn}$ ions. After dialysis, the solutions containing the $\mathrm{YCH}-\mathrm{Zn}$ complexes were collected and lyophilized for further analysis. Yak casein-Zn complexes were prepared according to the same procedure. All treatments were made in triplicate.

\section{Determination of Zinc-Binding Capacity}

After chelation treatment, Zn content in YC-Zn complex, YCH-Zn complex, and total Zn before binding reaction was measured by an atomic absorption spectrophotometer (TAS-986, Purkinje General Instruments Co. Ltd., Beijing, China). The Zn-binding capacity was calculated as follows:

Zn-binding capacity $=\frac{\mathrm{Zn} \text { content in complex }(\mathrm{g})}{\text { total Zn content in solution before binding }(\mathrm{g})} \times 100$

\section{Degree of Hydrolysis Determination}

The degree of hydrolysis $(\% D H)$ of the $\mathrm{YCH}$ obtained at different hydrolysis times with alcalase was determined following the procedures described by Mahmoud et al. (1992), and calculated according to the following equation:

$$
\% D H=\frac{A N_{h}-A N_{c}}{T N \times P_{f}} \times 100
$$

where $A N_{h}$ and $A N_{c}$ are the percent amino $\mathrm{N}$ of hydrolysate and intact casein, respectively. No significant difference was found between total $\mathrm{N}$ of the intact casein and that of the hydrolysates. Thus, $T N$ refers to the mean percent total $\mathrm{N}$ of the intact casein solution and all hydrolysate samples, and $P_{f}$ is a correction factor for side-chain $\mathrm{N}$, which cannot be converted to amino $\mathrm{N}$ by hydrolysis of peptide bonds. The $P_{f}$ was calculated from the AA profile of casein.

\section{Zinc-Releasing Percentage Determination}

Yak casein-Zn complexes and YCH-Zn complexes were dissolved in deionized water separately. The $\mathrm{pH}$ of these solutions was adjusted to 2.0, 3.0, 4.0, 5.0, 6.0, 7.0, 7.2, and 8.0 with $2 \mathrm{M} \mathrm{HCl}$ or $2 \mathrm{M} \mathrm{NaOH}$. After incubation in a shaking water bath for $2 \mathrm{~h}$ at $37^{\circ} \mathrm{C}$, the $\mathrm{Zn}$ amount in the supernatant and the total $\mathrm{Zn}$ in the solution were measured by an atomic absorption spectrophotometer. The Zn-releasing percentage was calculated as follows:

$$
\text { Zn-releasing } \%=\frac{\text { Zn amount in supernatant }(\mathrm{g})}{\text { total } \mathrm{Zn} \text { in solution }(\mathrm{g})} \times 100 \text {. }
$$

\section{Determination of Zinc Dialyzability and Solubility Under Simulated Gastrointestinal Conditions}

The dialyzability of $\mathrm{Zn}$ in $\mathrm{YC}-\mathrm{Zn}$ complexes, $\mathrm{YCH}-$ $\mathrm{Zn}$ complexes, and $\mathrm{Zn}$ acetate was examined according to the method described by Miller et al. (1981) and Wolfgor et al. (2002). Briefly, samples were digested with pepsin digestion mixture $(\mathrm{pH} 2)$ in beakers that were placed in a shaking water bath for $2 \mathrm{~h}$ at $37^{\circ} \mathrm{C}$. Then some samples were reacted with pancreatin and bile extract in dialysis bags ( $\mathrm{pH} 7.2)$ for another $2 \mathrm{~h}$. At the end of pancreatin-bile incubation, the dialysis bags were rinsed with water. In addition, samples were collected before and after pepsin treatment and after pancreatin-bile treatment. The $\mathrm{Zn}$ content was analyzed by an atomic absorption spectrophotometer. The Zn solubility after pepsin and pancreatin-bile treatment was calculated. The $\mathrm{Zn}$ dialyzability was expressed as a percentage of the total amount present in the pepsin digest, and was calculated as follows:

Zn dialyzability $(\%)=\frac{\text { total amount of dialyzed } \mathrm{Zn}(\mathrm{mg})}{\text { total } \mathrm{Zn} \text { in pepsin digest }(\mathrm{mg})} \times 100$.

\section{Structural Characterization of Yak Casein Hydrolysate-Zinc Complexes}

$\boldsymbol{U V}$-Visible Spectra. The UV-visible (UV-Vis) spectra of $\mathrm{YCH}$ and its $\mathrm{Zn}$ complex were recorded over the wavelength range of 200 to $800 \mathrm{~nm}$ by a UV-Vis spectrophotometer (UV-2102 PC, Shanghai, China).

FTIR Measurement. Fourier Transform Infrared Spectroscopy spectra of YCH-Zn complexes were ex- 
amined to demonstrate further whether $\mathrm{Zn}$ ions were indeed bound to the binding sites of $\mathrm{YCH}$. An appropriate amount of $\mathrm{YCH}$ or $\mathrm{YCH}-\mathrm{Zn}$ complex was mixed with dry $\mathrm{KBr}$. The mixture was ground into a fine powder and compressed into a disc. All spectra were recorded using an FTIR spectrometer (Perkin Elmer, Salem, MA) over a wavenumber region between 4,000 and $450 \mathrm{~cm}^{-1}$ at a resolution of $4 \mathrm{~cm}^{-1}$. A shift in absorbance at various wavenumbers was used as evidence of complex formation (Chaud et al., 2002).

\section{Statistical Analysis}

The sample treatments in the present study were run in triplicate and all analyses were performed in duplicate. Data were expressed as means \pm standard deviations. The differences between the means of the treatments were compared by one-way ANOVA at a significance level of $P<0.05$. Statistical analyses were performed with the SPSS package (SPSS 13.0 for windows, SPSS Inc., Chicago, IL).

\section{RESULTS}

\section{Zinc-Binding Capacity of Yak Casein Hydrolysates Prepared with Different Proteinases}

The Zn-binding capacity of YC and its hydrolysates obtained with different enzyme treatments was examined (Figure 1). Different enzymatic hydrolysates possessed different capacities to bind with $\mathrm{Zn}$. The effect of alcalase and trypsin hydrolysates was much greater than that of the other hydrolysates obtained with pepsin, Flavozyme, and papain $(P<0.05)$. The Zn-binding capacity of alcalase and trypsin hydrolysate did not show a significant difference $(P>0.05)$. Yak casein hydrolysate obtained with alcalase was used for further study because of the low final cost and the commercial availability of alcalase, which is readily available from microbial sources. In addition, it was interestingly found that the Zn-binding capacity of all kinds of casein hydrolysates was significantly lower than that of native casein itself $(P<0.05)$.

\section{Zinc-Binding Capacity of Yak Casein Hydrolysates Hydrolyzed by Alcalase for Different Periods}

The Zn-binding capacity of YC alcalase hydrolysates obtained at different hydrolysis periods ranged from 32.65 to $59.91 \%$ (Figure 2), which was markedly lower than that of YC itself (i.e., hydrolysis for $0 \mathrm{~h}$ ) of 92.23\% $(P<0.05)$. These results indicated that the degree of enzyme treatment (i.e., $\% D H$ ), influences the

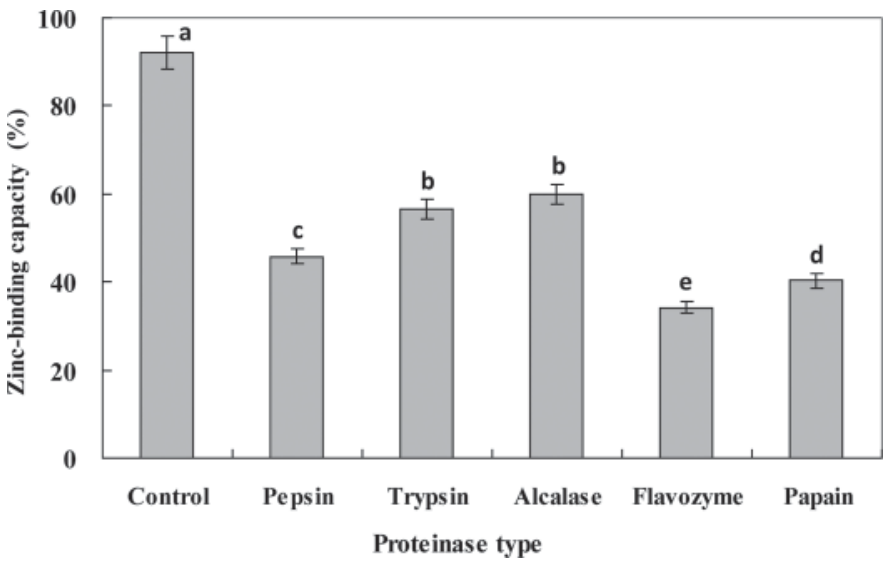

Figure 1. Zinc-binding capacity of yak casein enzymatic hydrolysates treated with pepsin, trypsin, alcalase, Flavozyme (Novo Nordisk Biochem Inc., Franklinton, NC), and papain. Yak casein with no enzyme treatment acted as a control group. Columns that do not share the same letter are significantly different from each other at $P<0.05$.

Zn-binding activity of the obtained casein hydrolysates. The Zn-binding capacity increased with the time of hydrolysis. The hydrolysate with a $\% D H$ of $22.84 \%$, obtained at the hydrolysis time of $6 \mathrm{~h}$, possessed the highest Zn-binding capacity of 59.91\%. However, if the hydrolysis time was too long, the Zn-binding ability decreased, which meant that hydrolysis time played an important role in the binding reaction between $\mathrm{YCH}$ and $\mathrm{Zn}$ ions.

\section{Zinc-Releasing Percentage of Yak Casein-Zinc Complexes and Yak Casein Hydrolysate-Zinc Complexes}

The Zn-releasing percentage of $\mathrm{YCH}-\mathrm{Zn}$ complexes, YC-Zn complexes, and $\mathrm{Zn}$ acetate at different $\mathrm{pH}$ values from 2.0 to 8.0 was investigated, as shown in Figure 3. The Zn-releasing percentage of YC-bound $\mathrm{Zn}$ was much lower than that of YCH-bound $\mathrm{Zn}$ at all of the tested $\mathrm{pH}$ values $(P<0.05)$. The $\mathrm{Zn}$-releasing amount in $\mathrm{YCH}-\mathrm{Zn}$ complexes was relatively stable in the $\mathrm{pH}$ range from 6.0 to 8.0; whereas that of $\mathrm{Zn}$ acetate decreased significantly from $96.20 \%$ at $\mathrm{pH} 6.0$ to $4.17 \%$ at $\mathrm{pH}$ 8.0. When the $\mathrm{pH}$ increased above 7.0, such as $\mathrm{pH}$ 7.2 and $\mathrm{pH}$ 8.0, the Zn-releasing amount of $\mathrm{YCH}$-bound $\mathrm{Zn}$ was significantly higher than that of YC-bound $\mathrm{Zn}$ and $\mathrm{Zn}$ acetate $(P<0.05)$. Higher $\mathrm{Zn}$-releasing percentage in this $\mathrm{pH}$ range is important for $\mathrm{Zn}$ bioavailability improvement. All of these findings suggest that hydrolysis treatment of $\mathrm{YC}$ by alcalase improves $\mathrm{Zn}$ solubilization and $\mathrm{Zn}$ solubility under intestinal $\mathrm{pH}$ values. In addition, the Zn-releasing amount of $\mathrm{YCH}-$ bound Zn was markedly lower than that of $\mathrm{Zn}$ salt at 


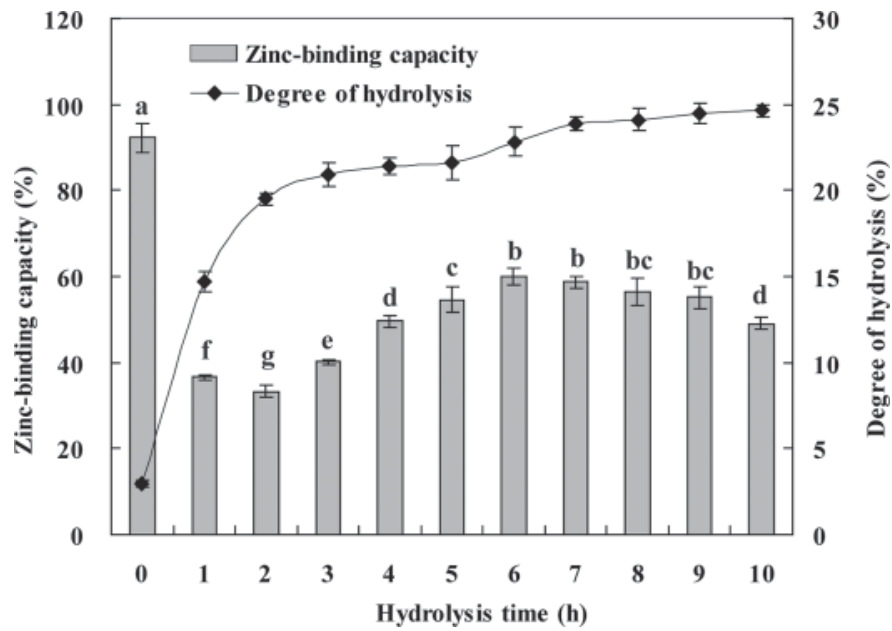

Figure 2. Time courses of zinc binding capacity and degree of hydrolysis $(\% \mathrm{DH})$ of yak casein hydrolysate obtained with alcalase at different hydrolysis time. Yak casein with no enzyme treatment acted as a control group (i.e., when hydrolysis time is $0 \mathrm{~h}$ ). Columns that do not share the same letter are significantly different from each other at $P<0.05$.

a $\mathrm{pH}$ range from 2.0 to 6.0 , which may be beneficial for body health. It was very interesting that the $\mathrm{Zn}$ releasing rate of $\mathrm{YC}$-bound $\mathrm{Zn}$ and $\mathrm{YCH}-$ bound $\mathrm{Zn}$ at $\mathrm{pH} 2.0$ was much higher than that at other $\mathrm{pH}$ values. However, further study is needed to better understand this observation.

\section{Zinc Solubility and Dialyzability Under Simulated Gastrointestinal Conditions}

Zinc solubility and dialyzability percentage after simulated gastrointestinal digestion of $\mathrm{Zn}$ acetate, $\mathrm{YC}$ $\mathrm{Zn}$ complex and $\mathrm{YCH}-\mathrm{Zn}$ complex were examined, and the results are summarized in Table 1 . The $\mathrm{Zn}$ dialyzability of YCH-Zn complexes was significantly higher than that of $\mathrm{YC}-\mathrm{Zn}$ complexes and inorganic $\mathrm{Zn}$ salt $(P<0.05)$. Although $\mathrm{Zn}$ salt was readily soluble in gastric conditions, its solubility decreased significantly under intestinal environment. The solubility of YC-Zn complexes was significantly lower than that of $\mathrm{YCH}-\mathrm{Zn}$ complexes after both pepsin digest and pancreatin-bile treatment, which may be the main reason for its lower dialyzability.

\section{UV-Vis Spectra of Yak Casein Hydrolysate-Zinc Complexes}

The UV-Vis absorption spectra of $\mathrm{YCH}$ obviously changed upon the addition of $\mathrm{Zn}^{2+}$, which resulted in several band shifts and intensity changes in the area of 230 to $300 \mathrm{~nm}$ (Figure 4). The absorbance maxima of $\mathrm{YCH}$ at 233 and $275 \mathrm{~nm}$ shifted to 230 and $279 \mathrm{~nm}$, respectively in YCH-Zn complexes, which meant that shift of the characteristic bands was observed with the addition of Zn. Furthermore, the absorbance of YCH-Zn

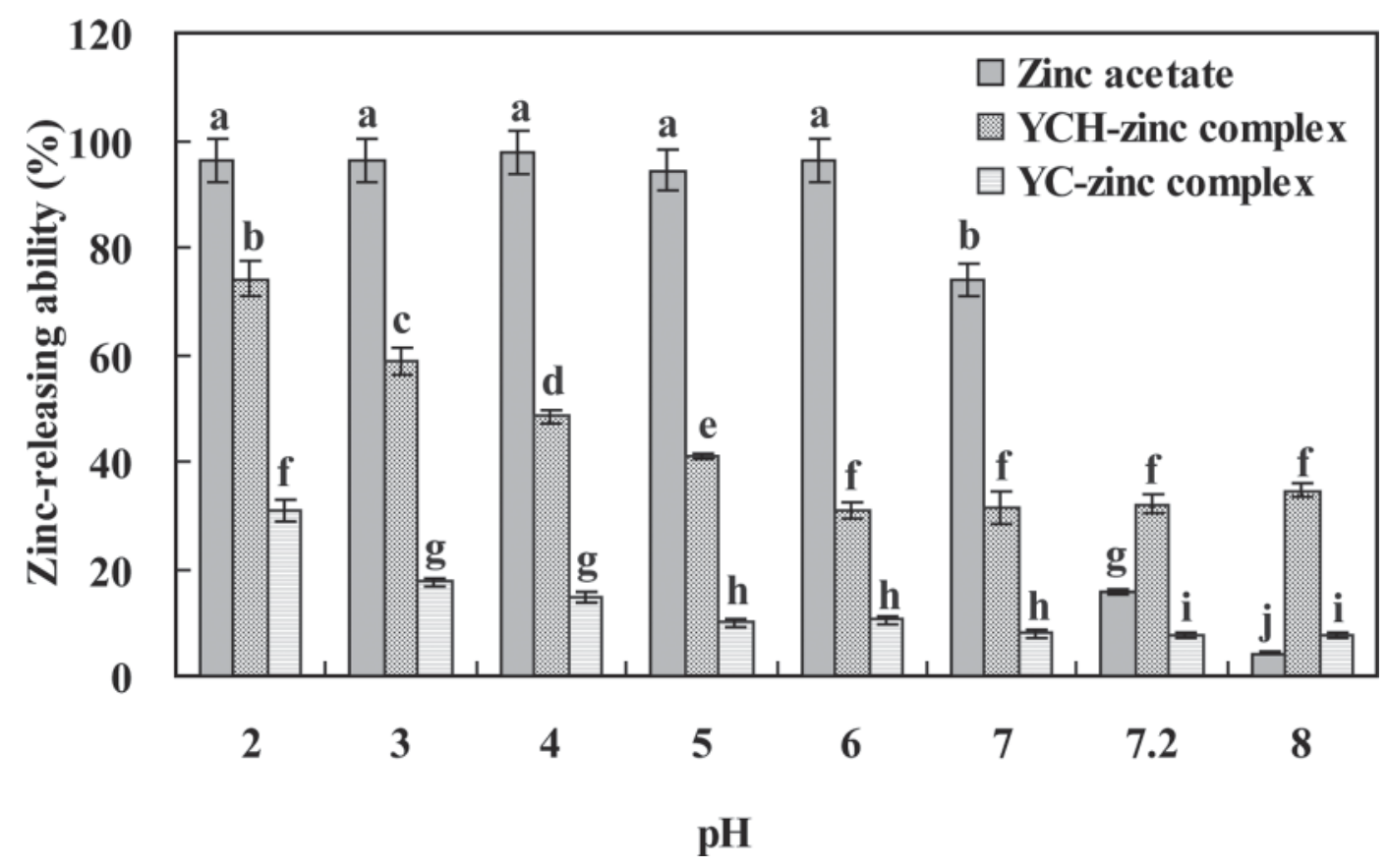

Figure 3. Zinc-releasing percentage of yak casein hydrolysate-zinc complex (YCH-zinc complex), yak casein-zinc complex (YC-zinc complex), and zinc acetate at different $\mathrm{pH}$ values of $2.0,3.0,4.0,5.0,6.0,7.0,7.2$, and 8.0. Columns that do not share the same letter are significantly different from each other at $P<0.05$. 
Table 1. The solubility and dialyzability of yak casein hydrolysate (YCH)-Zn complex, yak casein (YC)-Zn complex, and Zn acetate under simulated gastrointestinal conditions

\begin{tabular}{lccc}
\hline Item & $\begin{array}{c}\text { Solubility after } \\
\text { pepsin } \\
\text { treatment }(\%)\end{array}$ & $\begin{array}{c}\text { Solubility after } \\
\text { pancreatin-bile } \\
\text { treatment }(\%)\end{array}$ & $\begin{array}{c}\text { Dialyzability } \\
(\%)\end{array}$ \\
\hline Zn acetate & $96.5 \pm 3.43^{\mathrm{a}}$ & $21.88 \pm 1.22^{\mathrm{b}}$ & $18.22 \pm 1.21^{\mathrm{b}}$ \\
YC-Zn complex & $38.4 \pm 2.98^{\mathrm{c}}$ & $25.53 \pm 2.98^{\mathrm{b}}$ & $17.56 \pm 2.31^{\mathrm{b}}$ \\
YCH-Zn complex & $76.7 \pm 3.32^{\mathrm{b}}$ & $60.49 \pm 3.27^{\mathrm{a}}$ & $51.75 \pm 2.29^{\mathrm{a}}$ \\
\hline
\end{tabular}

${ }^{\mathrm{a}-\mathrm{c}}$ Means within a column followed by different superscript letters differ at $P<0.05$ level.

complexes at 270 to $300 \mathrm{~nm}$ is significantly lower than that of $\mathrm{YCH}$ itself. The main reason is that the oxygen atom of the carbonyl group in peptides binds with $\mathrm{Zn}^{2+}$ (Blindauer et al., 2009). The charge in the carbonyl group changes after the addition of $\mathrm{Zn}^{2+}$, which leads to the hypsochromic shift of its typical bands. All of these band shifts (i.e., the alterations in the area of characteristic absorbance of peptide bonds, suggest that $\mathrm{YCH}$ can bind with $\mathrm{Zn}$ ions and form YCH-Zn complexes.

\section{Characterization of FTIR Spectra of Yak Casein Hydrolysate-Zinc Complexes}

To gain further information about the type of interaction between ligand groups in $\mathrm{YCH}$ and $\mathrm{Zn}$ ions, FTIR studies were conducted to evaluate the formation and composition of $\mathrm{YCH}-\mathrm{Zn}$ complexes (Figure 5). After binding with Zn, some shifts occur in the complex, such as the wavenumber shift from 3,335 to
$3,323 \mathrm{~cm}^{-1}$, from 1,650 to $1,655 \mathrm{~cm}^{-1}$, and from 1,399 to $1,409 \mathrm{~cm}^{-1}$. The spectra of the YCH-Zn complexes also exhibit strong bands at wavenumbers of $1,655 \mathrm{~cm}^{-1}$ (amide I), corresponding to $\mathrm{C}=\mathrm{O}$ and $1,409 \mathrm{~cm}^{-1}$ (amide II), corresponding to $\mathrm{C}-\mathrm{N}$ and $\mathrm{N}-\mathrm{H}$. There are new strong bands at wavenumbers of $1118 \mathrm{~cm}^{-1}$ and $618 \mathrm{~cm}^{-1}$, corresponding to $\mathrm{O}-\mathrm{C}=\mathrm{O}$. The shifts of preexistent bands and the appearance of new absorbance peaks indicate that some bonds in $\mathrm{YCH}$ (peptide) can bind with $\mathrm{Zn}$ ions and form YCH-Zn complexes.

\section{DISCUSSION}

Zinc is one of the essential trace elements that play vital roles in human nutrition and health. Severe Zn deficiency clinically affects epidermal, gastrointestinal, central nervous, immune, and reproductive systems, and leads to dysfunctions related to these organs (Hambidge and Walravens, 1982). Many attempts are being

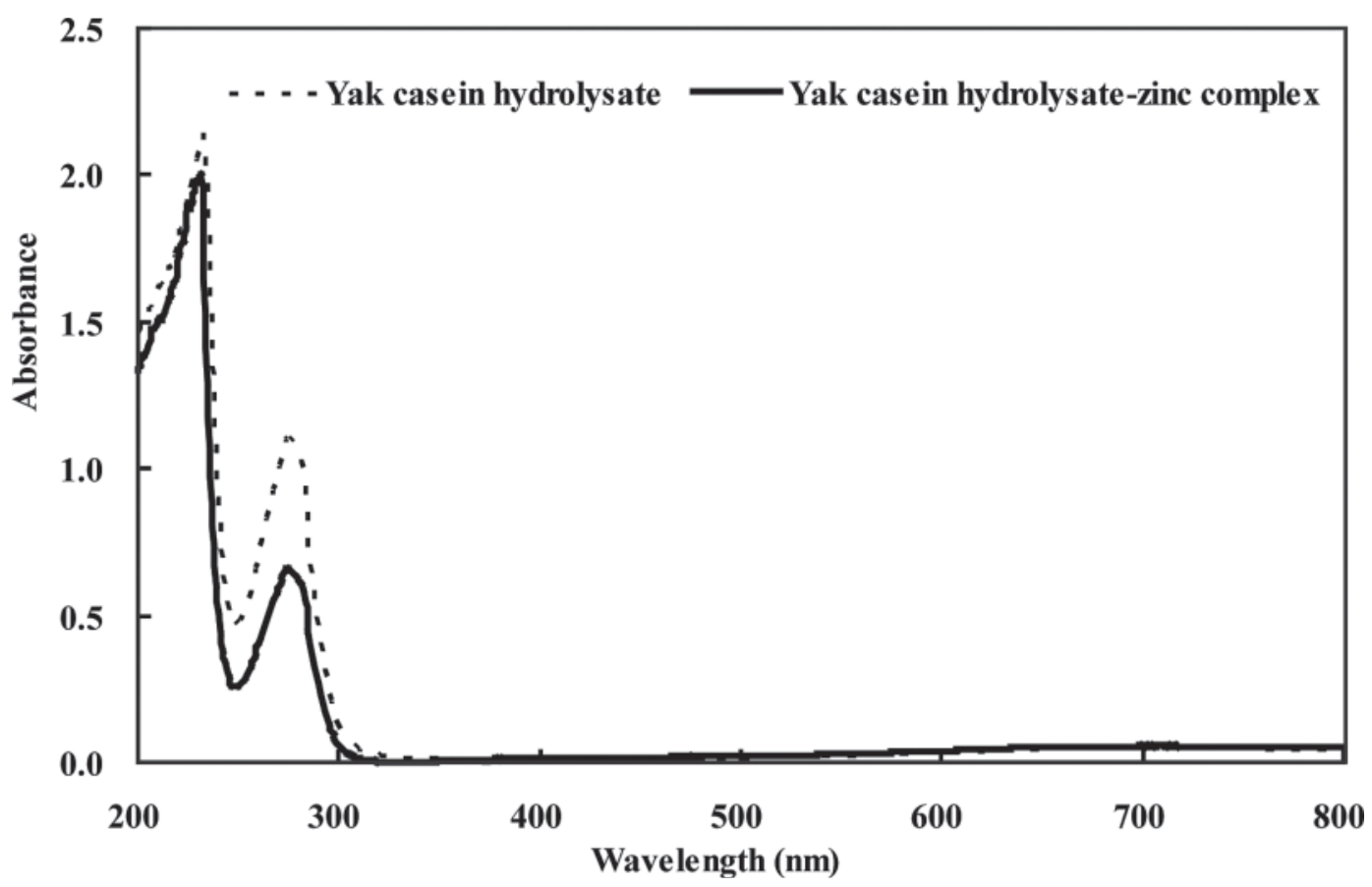

Figure 4. Ultraviolet-visible absorption spectra detection of yak casein hydrolysate and yak casein hydrolysate-zinc complex. 


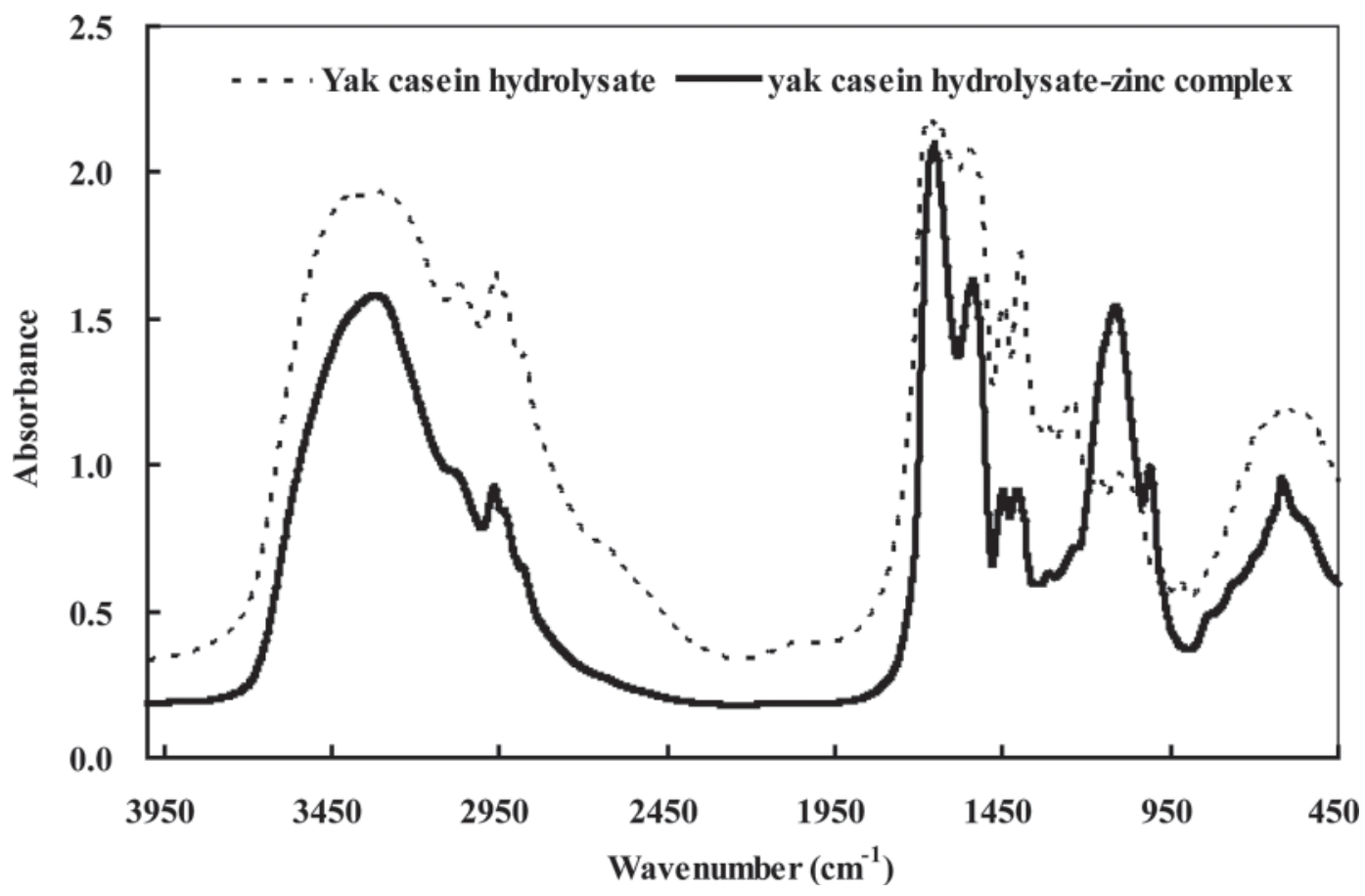

Figure 5. Fourier transform infrared spectroscopy (FTIR) spectra of yak casein hydrolysate-zinc complex and yak casein hydrolysate in the regions from $4,000 \mathrm{~cm}^{-1}$ to $450 \mathrm{~cm}^{-1}$.

made to increase the intake of Zn through mineral supplements. Milk has been chosen as one of the potential vehicles for mineral fortification because supplementation with milk or milk-based products has already exhibited positive effects on Zn nutritional status and on functional outcomes (Neumann et al., 2003; Whaley et al., 2003). Simulation of gastrointestinal digestion and dialysis are in vitro methods to assess mineral bioavailability (Miller et al., 1981; Perales et al., 2006). The present study shows that YCH possesses higher Zn-solubilizing activity and makes Zn more dialyzable compared with intact YC. The Zn-releasing percentage of YCH-Zn complexes was significantly higher than that of inorganic Zn salt and $\mathrm{YC}-\mathrm{Zn}$ complexes at basic $\mathrm{pH}$ conditions, which may indirectly demonstrate that YCH may have the potential to improve $\mathrm{Zn}$ bioavailability. The dialyzability test undertaken under simulated gastrointestinal digestion shows that $\mathrm{YCH}-\mathrm{Zn}$ complexes are more bioavailable than YC-Zn complexes and $\mathrm{Zn}$ salt. This result is in agreement with Drago and Valencia (2004) who reported that Zn dialyzability was adversely affected by casein content. The addition of milk and yogurt to a plant-based diet high in phytate increased Zn bioavailability (Rosado et al., 2005). The bioavailability of $\mathrm{Zn}$ with human milk was better than with cow milk or infant formulas (Casey et al., 1981). Some potentially important low-MW ligands in both human and bovine milk, such as citrate and glutamate, may facilitate intestinal absorption of metal, and the Zn-citrate complex was one of the predominant complexes (May et al., 1982). Reports also exist about other components in milk possessing the ability to improve Zn absorption. Casein phosphopeptides (CPP) may function as carriers of different minerals, and play an important role in their bioavailability (Clare and Swaisgood, 2000). Casein phosphopeptides could stimulate Zn absorption of infant foods for humans (Hansen et al., 1997) and decrease the inhibitory effect of phytate on Zn absorption from high-phytate infant diets in rats (Hansen et al., 1996). Casein phosphopeptides may prevent the precipitation of insoluble calcium phosphate in the distal intestine, and thereby increase the amount of soluble intraluminal calcium available for paracellular absorption between mucosal cells (Kitts and Yuan, 1992). The same mechanisms may be applied to the promoting effect on $\mathrm{Zn}$ solubility and dialyzability of $\mathrm{YCH}$ in the present study.

Although casein can form complexes with $\mathrm{Zn}$, the Zn-releasing amount and dialyzable percentage is limited under in vitro simulated conditions, which may be detrimental to the absorption of Zn. This result may partly explain the phenomena of some previous studies (Sandström et al., 1983; Lönnerdal, 2000), which showed that casein in cow milk had a negative effect on $\mathrm{Zn}$ absorption compared with whey protein. Casein micelles incorporated considerable amounts of $\mathrm{Zn}$, which 
resulted in the entrapment of $\mathrm{Zn}$ in casein curds formed in the stomach, which may be incompletely digested in the small intestine, thus rendering a significant proportion of Zn unavailable for absorption (Shen et al., 1995). The addition of milk and yogurt to a plant-based diet high in phytate increased Zn bioavailability, and the effect of yogurt was significantly higher than that of milk (Rosado et al., 2005), from which we can speculate that hydrolysis of milk protein is beneficial for its $\mathrm{Zn}$ absorption-improving effect because milk protein can be degraded by the action of proteolysis function of protease released by lactic acid bacteria. The improvement effect on $\mathrm{Zn}$ absorption can be attributed to the released peptides or AA that keep $\mathrm{Zn}$ ions in soluble form. The present study also shows that the lowering effect of Zn solubility and dialyzability due to casein can be offset by the hydrolysis process. Compared with native $\mathrm{YC}, \mathrm{YCH}$ makes $\mathrm{Zn}$ more soluble and dialyzable under intestinal $\mathrm{pH}$ conditions in the present study. The mechanism for this positive effect of $\mathrm{YCH}$ on $\mathrm{Zn}$ solubilization and dialyzability remains to be elucidated.

The changes in functional properties and bioactivities of casein are related to peptides produced by enzymatic hydrolysis. The specificity of the enzyme used for proteolysis and the degree of hydrolysis are important parameters for peptide release. Yak casein enzymatic hydrolysate shows great significance in Zn-binding and Zn-solubilization properties in the present study. The capacity of complex formation between $\mathrm{YCH}$ and $\mathrm{Zn}$ ions is clearly related to the electron-acceptor capacity of $\mathrm{Zn}^{2+}$ and the cation-acceptor ability of $\mathrm{YCH}$ as binding ligands. Zinc could be bound to CPP containing the phosphorylated cluster and phosphoserine residues (Miquel et al., 2006). Park and Allen (1998) reported that $\alpha_{\mathrm{s}}-\mathrm{CPP}$ had different patterns for $\mathrm{Ca}^{2+}$ binding than did $\beta-\mathrm{CN}$ phosphopeptides as the total $\mathrm{Ca}$ concentration was increased. The characteristics of $\mathrm{Ca}^{2+}$ binding to CPP differed from that characterized for the tryptic peptides. Peptides can both inhibit or enhance Fe absorption, depending on their nature (FairweatherTait and Hurrell, 1996). Hydrolysis of casein (Hurrell et al., 1989) or enzymic removal of the phosphorus groups from serine phosphate side chains largely removes its inhibitory effect (Hurrell et al., 1990). We are still not sure whether there are functional groups in $\mathrm{YC}$ peptides other than phosphoserine resides of CPP that contribute to $\mathrm{Zn}$ absorption. Therefore, peptides with Zn-binding ability and the potential Zn-binding sites in $\mathrm{YCH}$ still need further investigation.

In an attempt to confirm that the peptides in $\mathrm{YCH}$ possess Zn-binding capability, the Zn-binding properties of YCH were characterized by UV-Vis and FTIR methods. The spectra show that YCH really binds with $\mathrm{Zn}^{2+}$ and forms peptide- $\mathrm{Zn}$ complexes. Both spectra show that the absorption intensity of $\mathrm{YCH}$ changes upon the addition of $\mathrm{Zn}$ ions, which results in several shifts of their spectra. Ultraviolet-visible absorption has been successfully used in the evaluation of the metalchelation properties of phenolic acids by analyzing the shifts of UV bands characteristic of polyphenolic spectra (Asakura et al., 1990; Khokhar and Owusu Apenten, 2003). van der Ven et al. (2002) studied the FTIR spectra $\left(1800-800 \mathrm{~cm}^{-1}\right)$ of hydrolysates prepared from casein and whey proteins obtained with alcalase and pepsin, and found that the absorbencies of whey hydrolysates were lower in the range of 1,700 to $1,485 \mathrm{~cm}^{-1}$ and higher from 1,170 to $980 \mathrm{~cm}^{-1}$ when compared with that of casein hydrolysate. The FTIR spectra of casein hydrolysate were similar to the spectra in our samples (see Figure 5). The infrared spectra of $\mathrm{Fe}^{3+}$-peptide complexes also showed vibration and additional bands compared with that of casein hydrolysate (Chaud et al., 2002).

\section{CONCLUSIONS}

This study showed that YCH obtained through enzymatic treatment with alcalase possessed better Znbinding capacity, and higher Zn-releasing percentage compared with inorganic $\mathrm{Zn}$ salt. Also, YCH made Zn more dialyzable under a simulated gastrointestinal environment than did YC itself, which suggested that YCH-bound Zn may be more bioavailable. Yak casein hydrolysate with Zn-binding capacity, which was prepared by hydrolyzing casein with alcalase, may be a practical Zn-favoring ligand under most physiological conditions, and have potential in promoting Zn bioavailability. Therefore, YCH potentially may be used as a physiologically functional Zn-delivery vehicle in food systems. The composition and structure of $\mathrm{YCH}$, containing metal-binding loops or regions that were responsible for the effect on Zn bioavailability, still need further investigation. The current study has clearly established that hydrolysis of $\mathrm{YC}$ can effectively bind with Zn. Additional work (in vivo) to establish that such a complex has improved bioavailability is needed. Further, casein hydrolysates are bitter. Therefore, an effective way to deliver a palatable $\mathrm{YCH}-\mathrm{Zn}$ complex may need to be developed to allow its application in the food supply.

\section{ACKNOWLEDGMENTS}

We are grateful for the financial support of this work by the National Natural Science Foundation of China (Grant No. 30972291) and Beijing Natural Science Foundation (Grant No. 5102021). Authors thank Y. Zhao and Q. Wang (China Agricultural University) 
for their assistance with sample preparation. Special thanks are extended to S. X. Zhang (China Agricultural University) for her assistance with the FTIR analysis.

\section{REFERENCES}

Ait-Oukhatar, N., S. Bouhallab, F. Bureau, P. Arhan, J. L. Maubois, and D. L. Bouglé. 2000. In vitro digestion of caseinophosphopeptide-iron complex. J. Dairy Res. 67:125-129.

Alder-Nissen, J., ed. 1986. Determination of degree of hydrolysis of food proteins. Pages 57-69 in Enzymatic Hydrolysis of Food Proteins. Elsevier Applied Science Publishers, London, UK.

Asakura, T., Y. Nakamura, N. Inoue, M. Murata, and S. Homma. 1990. Characterization of zinc chelating compounds in instant coffee. Agric. Biol. Chem. 54:855-862.

Blindauer, C. A., I. Harvey, K. E. Bunyan, A. J. Stewart, D. Sleep, D. J. Harrison, S. Berezenko, and P. J. Sadler. 2009. Structure, properties, and engineering of the major zinc binding site on human albumin. J. Biol. Chem. 284:23116-23124.

Casey, C. E., P. A. Walravens, and K. M. Hambidge. 1981. Availability of zinc: Loading tests with human milk, cow's milk, and infant formulas. Pediatrics 68:394-396.

Chaud, M. V., C. Izumi, Z. Nahaal, T. Shuhama, M. D. Pires Bianchi, and O. De Freitas. 2002. Iron derivatives from casein hydrolysates as a potential source in the treatment of iron deficiency. J. Agric. Food Chem. 50:871-877.

Clare, D. A., and H. E. Swaisgood. 2000. Bioactive milk peptides: A prospectus. J. Dairy Sci. 83:1187-1195.

Drago, S. R., and M. E. Valencia. 2004. Influence of components of infant formulas on in vitro iron, zinc, and calcium availability. J. Agric. Food Chem. 52:3202-3207.

Fairweather-Tait, S., and R. F. Hurrell. 1996. Bioavailability of minerals and trace elements. Nutr. Res. Rev. 9:295-324.

Ferraretto, A., C. Gravaghi, A. Fiorilli, and G. Tettamanti. 2003. Casein-derived bioactive phosphopeptides: Role of phosphorylation and primary structure in promoting calcium uptake by HT-29 tumor cells. FEBS Lett. 551:92-98.

FitzGerald, R. J. 1998. Potential uses of caseinophosphopeptides. Int. Dairy J. 8:451-457.

Fredlund, K., M. Isaksson, L. Rossander-Hulthén, A. Almgren, and A.-S. Sandberg. 2006. Absorption of zinc and retention of calcium: Dose-dependent inhibition by phytate. J. Trace Elem. Med. Biol. 20:49-57.

Hambidge, K. M. 1986. Zinc. Pages 1-137 in Trace Elements in Human and Animal Nutrition. W. Mertz, ed. Academic Press, Orlando, FL.

Hambidge, K. M., and P. A. Walravens. 1982. Disorders of mineral metabolism. Clin. Gastroenterol. 11:87-117.

Hansen, M., B. Sandström, M. Jensen, and S. S. Sørensen. 1997. Casein phosphopeptides improve zinc and calcium absorption from rice-based but not from whole-grain infant cereal. J. Pediatr. Gastroenterol. Nutr. 24:56-62.

Hansen, M., B. Sandström, and B. Lönnerdal. 1996. The effect of casein phosphopeptides on zinc and calcium absorption from high phytate infant diets assessed in rat pups and Caco-2 cells. Pediatr. Res. 40:547-552.

Harzer, G., and H. Kauer. 1982. Binding of zinc to casein. Am. J. Clin. Nutr. 35:981-987.

Hurrell, R. F., R. Berrocal, S. R. Lynch, S. A. Dassenko, and J. D. Cook. 1990. The influence of bovine milk proteins on iron absorption in man. Pages 124-178 in Recent Knowledge on Iron and Folate Deficiencies in the World. S. Hercberg, P. Galan, and H. Dupin, ed. Colloque INSERM, Paris, France.

Hurrell, R. F., S. R. Lynch, T. P. Trinidad, S. A. Dassenko, and J. D. Cook. 1989. Iron absorption in humans as influenced by bovine milk proteins. Am. J. Clin. Nutr. 49:546-552.

Kamijima, T., A. Ohmura, T. Sato, K. Akimoto, M. Itabashi, M. Mizuguchi, M. Kamiya, T. Kikukawa, T. Aizawa, M. Takahashi, K. Kawano, and M. Demura. 2008. Heat-treatment method for producing fatty acid-bound alpha-lactalbumin that induces tumor cell death. Biochem. Biophys. Res. Commun. 376:211-214.

Khokhar, S., and R. K. Owusu Apenten. 2003. Iron binding characteristics of phenolic compounds: Some tentative structure-activity relations. Food Chem. 81:133-140.

Kim, S. B., I. S. Seo, M. A. Khan, K. S. Ki, M. S. Nam, and H. S. Kim. 2007. Separation of iron-binding protein from whey through enzymatic hydrolysis. Int. Dairy J. 17:625-631.

Kitts, D. D., and Y. V. Yuan. 1992. Caseinophosphopeptides and calcium bioavailability. Trends Food Sci. Technol. 3:31-35.

Lönnerdal, B. 2000. Dietary factors influencing zinc absorption. J. Nutr. 130:1378S-1383S.

Mahmoud, M. I., W. T. Malone, and C. T. Cordle. 1992. Enzymatic hydrolysis of casein: Effect of degree of hydrolysis on antigenicity and physical properties. J. Food Sci. 57:1223-1229.

Mao, X.-Y., M. Li, M. Li, S.-P. Xu, C.-C. Xu, J.-N. Gu, F. Z. Ren, and K.-X. Liu. 2008. Effects of different factors on chelating activity of casein enzymatic hydrolysate with ferrous salt. Food Sci. 29:145-148. (in Chinese).

Mao, X.-Y., J.-R. Ni, W.-L. Sun, P.-P. Hao, and L. Fan. 2007a. Value-added utilization of yak milk casein for the production of angiotensin-I-converting enzyme inhibitory peptides. Food Chem. 103:1282-1287.

Mao, X. Y., H. Y. Yang, J. P. Song, Y. H. Li, and F. Z. Ren. 2007b. Effect of yak milk casein hydrolysate on Th1/Th2 cytokines production by murine spleen lymphocytes in vitro. J. Agric. Food Chem. 55:638-642.

Maret, W., and H. H. Sandstead. 2006. Zinc requirements and the risks and benefits of zinc supplementation. J. Trace Elem. Med. Biol. 20:3-18

May, P. M., G. L. Smith, and D. R. Williams. 1982. Computer calculation of zinc(II)-complex distribution in milk. J. Nutr. 112:19901993.

Miller, D. D., B. R. Schricker, R. R. Rasmussen, and D. Van Campen. 1981. An in vitro method for estimation of iron availability from meals. Am. J. Clin. Nutr. 34:2248-2256.

Miquel, E., A. Alegría, R. Barberá, and R. Farré. 2006. Casein phosphopeptides released by simulated gastrointestinal digestion of infant formulas and their potential role in mineral binding. Int. Dairy J. 16:992-1000.

Miquel, E., and R. Farré. 2007. Effects and future trends of casein phosphopeptides on zinc bioavailability. Trends Food Sci. Technol. 18:139-143.

Narva, M., M. Kärkkäinen, T. Poussa, C. Lamberg-Allardt, and R. Korpela. 2003. Caseinphosphopeptides in milk and fermented milk do no affect calcium metabolism acutely in postmenopausal women. J. Am. Coll. Nutr. 22:88-93.

Neumann, C. G., N. O. Bwibo, S. P. Murphy, M. Sigman, S. Whaley, L. H. Allen, D. Guthrie, R. E. Weiss, and M. W. Demment. 2003 Animal source foods improve dietary quality, micronutrient status, growth and cognitive function in Kenyan school children: Background, study design and baseline findings. J. Nutr. 133:3941S3949S.

Ochirkhuyag, B., J. M. Chobert, M. Dalgalarrondo, Y. Choiset, and T. Haertlé. 1997. Characterization of caseins from Mongolian yak, khainak, and Bactrian camel. Lait 77:601-613.

Park, O., and J. C. Allen. 1998. Preparation of phosphopeptides derived from $\alpha_{\mathrm{s}}$-casein and $\beta$-casein using immobilized glutamic acidspecific endopeptidase and characterization of their calcium binding. J. Dairy Sci. 81:2858-2865.

Perales, S., R. Barberá, M. J. Lagarda, and R. Farré. 2006. Bioavailability of zinc from infant foods by in vitro methods (solubility, dialyzability and uptake and transport by Caco-2 cells). J. Sci. Food Agric. 86:971-978.

Peres, J. M., S. Bouhallab, F. Bureau, J. L. Maubois, P. Arhan, and D. Bouglé. 1997. Digestive absorption of iron bound to the 1-25 caseinophosphopeptide of $\beta$-casein. Lait 77:433-440.

Rosado, J. L., M. Diaz, K. Gonzalez, I. Griffin, S. A. Abrams, and R. Preciado. 2005. The addition of milk or yogurt to a plant-based diet increases zinc bioavailability but does not affect iron bioavailability in women. J. Nutr. 135:465-468. 
Sandström, B. A. C., A. Cederblad, and B. Lönnerdal. 1983. Zinc absorption from human milk, cow's milk, and infant formulas. Am. J. Dis. Child. 137:726-729.

Shen, L., H. Robberecht, P. Van Dael, and H. Deelstra. 1995. Estimation of the bioavailability of zinc and calcium from human, cow's, goat, and sheep milk by an in vitro method. Biol. Trace Elem. Res. 49:107-118.

Svenning, C., and G. E. Vegarud. 1998. Page 12 in the Proceedings of the Dairy Foods in Health, IDF Nutrition Week, Wellington, New Zealand.

van der Ven, C.. S. Muresan, H. Gruppen, D. B. A. de Bont, K. B Merck, and A. G. J. Voragen. 2002. FTIR spectra of whey and casein hydrolysates in relation to their functional properties. J. Agric. Food Chem. 50:6943-6950.
Vegarud, G. E., T. Langsrud, and C. Svenning. 2000. Mineral-binding milk proteins and peptides: Occurrence, biochemical and technological characteristics. Br. J. Nutr. 84(Suppl. 1):S91-S98.

Webb, E. C. 1992. Enzyme Nomenclature. IUBMB. Academic Press, New York, NY.

Whaley, S. E., M. Sigman, C. Neumann, N. Bwibo, D. Guthrie, R. E. Weiss, S. Alber, and S. P. Murphy. 2003. The impact of dietary intervention on the cognitive development of Kenyan school children. J. Nutr. 133:3965S-3971S.

Wolfgor, R., S. R. Drago, V. Rodriguez, N. R. Pellegrino, and M. E. Valencia. 2002. In vitro measurement of available iron in fortified foods. Food Res. Int. 35:85-90. 